\title{
Gramsci e Mannheim: conceitos clássicos sobre intelectuais
}

\author{
Ana Carolina Quintana de Serpa Vieira ${ }^{1}$ \\ Marco Antonio Perruso ${ }^{2}$
}

\section{Resumo}

O presente artigo trata dos aparatos conceituais de dois autores clássicos e pioneiros nos estudos a respeito de intelectuais: Antonio Gramsci e Karl Mannheim. Buscamos rever diretamente suas pesquisas e reflexões sobre o tema, analisando e comparando sociologicamente seus respectivos conceitos e observações, bem como levando em conta certos aspectos históricos de suas próprias trajetórias intelectuais. A relevância e a diversidade da recepção e do uso de seus arsenais teóricos correspondentes contrastam com a escassez de trabalhos exatamente sociológicos sobre os conceitos relativos a intelectuais de Gramsci e Mannheim, no contexto acadêmico brasileiro. Os dois autores foram contemporâneos e se debruçaram sobre a temática adotando perspectivas analíticas antagônicas. Gramsci analisa os intelectuais e os classifica numa tipologia que torna-se referência categorial e política, ao passo que Mannheim lança mão e acaba por consagrar teoricamente o conceito de intelligentsia. Exploramos, então, a oposição sociológica entre intelectualidade gramsciana e intelligentsia mannheimiana, a qual envolve significativas implicações sociais, políticas e culturais nas sociedades modernas e contemporâneas.

Palavras-chave: intelectuais; Gramsci; Mannheim

\section{Gramsci and Mannheim: classic concepts about intellectuals}

Abstract

This article deals with the concepts of two classic authors and pioneers in the studies on intellectuals: Antonio Gramsci and Karl Mannheim. We seek to directly review their research and reflections on the subject, analyzing and comparing sociologically their respective concepts and comments, as well as taking into account certain historical aspects of their own intellectual trajectories. The relevance and diversity of the reception and use of their corresponding theoretical arsenals contrasts with the scarcity of precisely sociological works on their concepts related to intellectuals in the Brazilian academic context. The two authors were contemporaries and focused on the theme adopting antagonistic analytical perspectives. Gramsci analyzes the intellectuals and classifies them into a typology that becomes a categorical and political reference, while Mannheim proposes and ends up theoretically consecrating the concept of the intelligentsia. We then explore the sociological opposition between intellectuality in Gramsci and intelligentsia in Mannheim, which has significant social, political and cultural implications in modern and contemporary societies.

Keywords: intellectuals; Gramsci; Mannheim

1 Professora de Sociologia da Secretaria de Educação do Estado do Rio de Janeiro e Mestre em Ciências Sociais pelo Programa de Pós-Graduação em Ciências Sociais da Universidade Federal Rural do Rio de Janeiro (UFRRJ).

2 Professor Associado de Sociologia do Departamento de Ciências Sociais e do Programa de Pós-Graduação em Ciências Sociais, da Universidade Federal Rural do Rio de Janeiro (UFRRJ). 


\section{Introdução}

O presente artigo trata dos aparatos conceituais de dois autores clássicos e pioneiros nos estudos a respeito de intelectuais: Antonio Gramsci e Karl Mannheim. Dada a grande importância e disseminação das obras desses autores no mundo das ciências sociais e humanas em geral, buscamos rever diretamente suas pesquisas e reflexões sobre a intelectualidade, analisando e comparando sociologicamente seus respectivos conceitos, bem como levando em conta certos aspectos históricos de suas trajetórias intelectuais que nos remetem a determinadas implicações teóricas.

A justificativa e a oportunidade deste artigo se apresentam face à escassez de trabalhos exatamente sociológicos sobre os conceitos relativos a intelectuais de Gramsci e Mannheim, no Brasil, o que contrasta fortemente com a relevância e a diversidade da recepção e do uso de seus arsenais teóricos correspondentes até os dias atuais - para não mencionar as obras de ambos em sua totalidade, estas sim vastamente investigadas entre nós. De fato, trabalhos diretamente comparativos entre ambos parecem inexistir na sociologia brasileira. Mais amplamente nas ciências humanas, se destaca o artigo de Vieira (2008), que aborda as obras de Gramsci, Mannheim e Bourdieu sob a ótica da história intelectual em interface com a educação - e que será um interlocutor nosso no presente artigo $^{3}$.

Outros trabalhos são dedicados às teorias gramsciana e mannheimiana dos intelectuais, isoladamente. Sobre Gramsci, por exemplo, Bosi (1975) e Duriguetto (2014), nos campos disciplinares da cultura/literatura e do serviço social, respectivamente. Em relação a Mannheim, e nas próprias ciências sociais: Matias (2007) e Shiota (2009). Registre-se que há trabalhos cuja ênfase está em temas que, embora correlatos, fogem ao escopo deste artigo: a sociologia do conhecimento de Mannheim (CEPÊDA, MAZUCATO \& FONTANA, 2015) ou a produção de Gramsci sobre a educação (NOSELLA, 2004). Há, ainda, estudos que tratam da influência desses dois autores na intelectualidade e pensamento político-social nacionais, caso de Lynch (2016), entre outros trabalhos na ciência política $e$ sociologia brasileiras.

As obras aqui revistas de Gramsci e Mannheim são as seguintes: do primeiro, Os intelectuais e a organização da cultura; do segundo, Ideologia e utopia e Sociologia da cultura. ${ }^{4}$

A obra gramsciana em tela é a edição brasileira do original na língua italiana, que data de 1949. Sabe-se que Gramsci nunca escreveu obra com tal título, tendo sido opção dos então editores do já falecido militante comunista italiano organizar tematicamente a publicação dos cadernos em que deixou anotadas suas pesquisas e reflexões realizadas no cárcere do fascismo, entre 1926 e 1935 (BIANCHI, 2007, p. 7).

Do mesmo período são Ideologia e Utopia, que data de 1929, e Sociologia da cultura, escrita em 1932 mas organizada/publicada postumamente, já na década de $1950^{5}$. Mannheim era húngaro, mas passou boa parte de sua vida profissional como professor universitário na Alemanha, nos anos 1920/30. Após a ascensão do nazismo ao poder, radicou-se na Inglaterra.

3 A par de tal contexto, a motivação inicial para o presente artigo se deu no bojo das pesquisas de pós-doutorado de um dos autores, junto ao Departamento de Ciência Política da Universidade de São Paulo, sob supervisão de Bernardo Ricupero. Na perspectiva de fazer dialogar a sociologia dos intelectuais com os estudos na área do pensamento social e político brasileiro, pôde-se notar certa ausência de precisão conceitual relativa aos intelectuais em trabalhos clássicos do pensamento nacional, razão pela qual investiu-se no presente artigo. Houve então o encontro de tais preocupações com as pesquisas de outro dos autores, dedicadas às relações entre intelectuais, sociologia e educação no Brasil. Há previsão de confecção de outro trabalho, em continuidade a este, tratando das conceituações de Pierre Bourdieu e Michael Burawoy sobre intelectuais

4 Agradecemos a Daniela Mussi e Thiago Mazucato por alguns esclarecimentos prestados a respeito das publicações das obras de Gramsci e Mannheim, respectivamente.

5 Em Sociologia da cultura, Mannheim teria se defendido de más compreensões ocorridas na recepção de Ideologia e Utopia (MANNHEIM, 2001, p. 82). 
Gramsci, inovando no campo do marxismo, refletiu a respeito dos intrincados processos de modernização sócio-cultural e de centralização política na Itália, acabando por perecer na prisão imposta pelo regime fascista que combateu. Já Mannheim, partindo intelectualmente do historicismo alemão, se debruçou sobre os desafios enfrentados pela modernidade e pela racionalidade em suas trajetórias históricas de consolidação e crise, explicitadas por experiências que viveu, desde a República de Weimar até a ascensão e queda do nazismo.

Os dois autores, portanto, foram contemporâneos e se interessaram pela mesma temática, apesar de adotarem perspectivas antagônicas a respeito da intelectualidade, como pretendemos ressaltar no presente artigo. Gramsci analisa os intelectuais e os classifica numa tipologia que torna-se referência categorial e política, ao passo que Mannheim lança mão e acaba por consagrar teoricamente o conceito de intelligentsia ${ }^{6}$.

Passemos então à contextualização teórica e ao exame, que se quer minucioso, dos conceitos e das implicações analíticas e sociológicas das obras de ambos autores no que tange aos intelectuais - suas determinações e interações sociais, seus espaços de atuação, suas ações e impactos na sociedade.

\section{Intelectuais e sociedade}

A reflexão e a pesquisa de Gramsci sobre os intelectuais tendem a enfatizar as relações entre a sociedade - suas classes, seus grupos sociais componentes - e os setores intelectualizados como imprescindíveis à compreensão dos intelectuais. É assim que o comunista italiano se pergunta: os intelectuais são um grupo autônomo ou cada grupo social possui seus intelectuais? (GRAMSCI, 1985, p. 3) Ele responde a esta indagação afirmando que tal questão, de grande complexidade histórica, comporta dois modos principais de formação dos intelectuais.

No primeiro, cada grupo social, nascido de uma função essencial na produção econômica (nexo ontológico das classes sociais), cria para si, organicamente, uma ou mais camadas de intelectuais, que dão homogeneidade e autoconsciência sócio-política ao grupo. Assim, por exemplo, a burguesia emergente com o capitalismo cria o técnico da indústria. $\mathrm{O}$ empresário já indica uma elaboração social superior, pois possui certa capacidade dirigente, organizativa e técnica, ou seja, intelectual - o que não quer dizer que todo o empresariado se configure como intelectualidade, mas ao menos uma parte ou uma elite sua. Ou então cada grupo/ classe social é capaz de escolher seus prepostos, isto é, seus intelectuais. Os intelectuais orgânicos de cada nova classe, para Gramsci, normalmente originam-se de especializações da tarefa/função original da classe a que pertence. (GRAMSCI, 1985 , p. 3-4) ${ }^{7}$.

Mas o marxista italiano percebe exceções importantes a esse primeiro modo de formação dos intelectuais:

\begin{abstract}
“(...) cabe observar que a massa dos camponeses, ainda que desenvolva uma função essencial no mundo da produção, não elabora seus próprios intelectuais 'orgânicos' e não 'assimila' nenhuma camada de intelectuais 'tradicionais', embora outros grupos sociais extraiam da massa dos camponeses muitos de seus intelectuais e grande parte dos intelectuais tradicionais seja de origem camponesa." (GRAMSCI, 1985, p. 5)
\end{abstract}

Surge pois, em oposição aos intelectuais orgânicos, a segunda modalidade de formação dos intelectuais, consubstanciando os intelectuais tradicionais. A conceituação gramsciana em torno dos intelectuais envolve assim, em grau significativo, uma variedade de relações sóciohistóricas: um grupo ou classe social pode 
possuir ou não seus intelectuais, orgânicos ou tradicionais, bem como pode fornecer intelectuais para outros grupos/classes.

Cada camada social nova encontra setores intelectuais pré-existentes, os quais, inclusive, impõem uma percepção de permanência histórica - como foi o caso da burguesia europeia, que deparou-se com um setor dominante intelectualmente durante todo o período histórico caracterizado pelo feudalismo: o clero. Modelo de intelectualidade tradicional na tipologia gramsciana, os eclesiásticos medievais monopolizaram a produção de ideias e ideologias antes da modernidade.

Ainda no que concerce à efetividade histórica de intelectuais orgânicos e tradicionais, Gramsci aponta que as classes sociais que lutam para ser dominantes almejam, simultaneamente, conquistar intelectuais tradicionais e criar seus próprios intelectuais orgânicos, sendo o primeiro objetivo alcançado na medida do sucesso do segundo (GRAMSCI, 1985, p. 9 e 101).

É possível afirmar, a partir da obra de Gramsci, que os intelectuais orgânicos costumam ser provenientes da sua classe social de origem, mantendo seu vínculo a ela como porta-vozes dos seus interesses e ideologias de classe. Ainda que oriundos de outro setor social, são mesmo assim orgânicos na medida em que se intelectualizaram por meio da experiência da classe que os assimilou - que tanto pode ser a dominante como uma classe dominada. Neste sentido, inclusive, os intelectuais atuam visando a manutenção ou a transformação da sociedade. Os intelectuais tradicionais, por sua vez, já existem enquanto tais antes de serem envolvidos pela experiência inovadora de um setor social ascendente.

Gramsci também questiona a respeito da abrangência do conceito de intelectual, se existiria um critério unitário que identificasse todas as atividades intelectuais, distinguindo os intelectuais de outros grupos sociais. Ele identifica que o erro metodológico principal nessa questão consiste em buscar tal critério no que seria intrínseco às atividades intelectuais, “ao invés de buscá-lo no conjunto do sistema de relações no qual estas atividades (e, portanto, os grupos que as personificam) se encontram, no conjunto geral das relações sociais" (GRAMSCI, 1985, p. 7).

Neste ponto evidencia-se que Gramsci percebe os intelectuais enquanto indivíduos socialmente contextualizados, antes que como uma camada dotada de qualificações técnicas ou particularidades exclusivas, separada do restante da sociedade. Desta forma, evita-se um enfoque essencialista na análise dos intelectuais, privilegiando uma dimensão teórica relacional que não olvida o conjunto da sociedade.

Assim, Gramsci entende que o operário moderno não se define pelo trabalho manual, mas por trabalhar em determinadas condições e relações sociais. Não existe trabalho unicamente mental ou unicamente físico. Todo proletário lança mão de um mínimo de qualificação técnica e de "atividade intelectual criadora" (GRAMSCI, 1985, p. 7). Ademais, o chamado trabalhador braçal sempre desenvolve atividades intelectuais fora de seu período laboral. Pode-se então falar de intelectuais, mas nunca de nãointelectuais: "Todos os homens são intelectuais, poder-se-ia dizer então: mas nem todos os homens desempenham na sociedade a função de intelectuais" (GRAMSCI, 1985, p. 7).

$\mathrm{Na}$ análise gramsciana o exercício intelectual está difuso na sociedade, mas comumente atinge um grau qualitativamente superior e especializado em alguns indivíduos e setores sociais, embora não por eventuais qualidades ou atributos inerentes a essas pessoas ou coletividades, mas sim por conta de estruturas societárias que propiciam a concentração da atividade intelectual neles. Esse tipo de análise desenvolvida por Gramsci põe em jogo com mais força as interações sociais dinâmicas que envolvem as atividades intelectuais de uma sociedade, em detrimento de um olhar privilegiado sobre quais seriam as características distintivas da intelectualidade.

Para o autor italiano, a função social dos intelectuais está referida ao desenvolvimento de concepções de mundo capazes de influenciar toda a sociedade. E tal desenvolvimento origina- 
se da necessidade, que cada nova camada intelectual possui, de elaboração crítica da atividade intelectual presente nas novas práticas concretas do grupo ou classe social a que pertence, de maneira que estas práticas tornemse o fundamento de uma nova concepção de mundo e sociedade. O intelectual, então, é entendido como o organizador da cultura, que assim procede legitimando a posição de classe a que corresponde ou a que serve (VIEIRA, 2008, p. 76). Para Gramsci, tal processo se deu com a burguesia por ocasião do advento e consolidação do capitalismo - cumprindo a educação papel fundamental, por conta da maior complexidade da produção econômica moderna e, principalmente, da dominação social moderna - e o mesmo se dará com o proletariado no socialismo (GRAMSCI, 1985, p. 6-8; também p.14-15).

Mannheim contextualiza socialmente a intelectualidade de maneira diversa de Gramsci. A sociologia dos intelectuais do autor húngaro, sob influência das teorias sociais de Max Weber e Georg Simmel, enfatiza as transformações culturais impulsionadas pelo advento da modernidade. As sociedades modernas e suas múltiplas conflituosidades faziam colapsar as visões de mundo abstratas e universalizantes oriundas do Iluminismo, bem comoquestionavam a suposta pureza do conhecimento científico, de maneira que emergia uma nova forma de pensar pautada na reflexão social do conhecimento:

"Nossa época caracteriza-se não só por uma crescente autoconsciência como também por nossa capacidade de determinar a natureza concreta dessa consciência: vivemos num tempo de existência social consciente. Este processo de auto-esclarecimento começou de baixo para cima." (MANNHEIM, 2001, p. 73)

Nas sociedades modernas, Mannheim registra, mudanças significativas ocorrem no campo da cultura, do conhecimento, da ciência, da educação, da ideologia, fazendo crescer o papel dos intelectuais na explicação sociológica do mundo e impactando de modos diferentes os vários estratos sociais: "Mas é só no pensamento do proletariado que a perspectiva sociológica tornou-se globalizante. $\mathrm{O}$ proletariado foi $\mathrm{o}$ primeiro grupo a propor-se uma auto-avaliação sociológica consistente e a adquirir uma consciência de classe sistemática" (MANNHEIM, 2001, p. 74).

Não poderia ser de outra maneira numa sociedade como a moderna, mais dinâmica que a sociedade tradicional anterior e onde, portanto, os referenciais sociais são mais móveis. Cada grupo social não mais "se percebe em termos fixos e definitivos", pelo contrário, aspira "sempre a transcender e reconstruir a si próprio" (MANNHEIM, 2001, p. 69-70).

É neste enquadramento que Mannheim traça o que seria a origem moderna da independência social da intelligentsia. Ao proliferar discrepâncias entre predisposições sociais adquiridas e situações sociais novas, desenvolvem-se sensações de incômodo que podem evoluir para reflexões mais profundas sobre as constantes mudanças enfrentadas, as quais sustentarão processos de intelectualização que andam passo-a-passo com dinâmicas de desvinculação social dos intelectuais (MANNHEIM, 2001, p. 118).

Neste ínterim, Mannheim introduz seu conceitual, ressaltando - de forma oposta à Gramsci - a autonomia da intelectualidade diante dos demais grupos sociais:

"O surgimento da intelligentsia marca a última fase do crescimento da consciência social. A intelligentsia foi o último grupo a adotar o ponto de vista sociológico, pois sua posição na divisão social do trabalho não lhe propicia acesso direto a nenhum segmento vital e ativo da sociedade. $\mathrm{O}$ gabinete recluso e a dependência livresca só permitem uma visão derivada do processo social. Não é por acaso que essa camada ignorou por tanto tempo o caráter social da mudança. E os que finalmente se mostraram sensíveis ao pulso social de seu tempo encontraram o caminho para uma apreciação sociológica de sua própria posição bloqueado pelo proletariado." (MANNHEIM, 2001, p. 77-78) 
O autor húngaro, pois, vai antes destacar os agrupamentos sociais intelectualizados que observar a atividade intelectual difusa na sociedade - como se dá preferencialmente na perspectiva gramsciana:

“Assim, quem pensa não são os homens em geral, nem tampouco os indivíduos isolados, mas os homens em certos grupos que tenham desenvolvido um estilo de pensamento particular em uma interminável série de respostas a certas situações típicas características de sua posição comum." (MANNHEIM, 1986, p. 31)

\section{A intelligentsia na concepção} mannheimiana vai se desenhando como um grupo social de estatuto singular na sociedade moderna, enquanto em Gramsci a inteligibilidade sociológica dos intelectuais passa por seus vínculos com as classes sociais em luta umas com as outras. O peso do enquadramento marxista original da sociedade moderna em sua dimensão estruturante capitalista parece incomodar Mannheim e demandar uma resposta teórica nova a respeito da intelectualidade. Uma pista neste sentido reside no tom quase de lamento com que ele percebe a força da visão de mundo autocentrada produzida pelo proletariado, a mudar a atitude histórica genérica da intelligentsia: "seu velho orgulho deu lugar à subserviência” (MANNHEIM, 2001, p. 78).

Critica ele, pois, as análises sobre os intelectuais realizadas sob o prisma materialista: "esse procedimento pouco sutil apenas afirma que há uma relação entre conflito de classe e ideação, desprezando os elos intervenientes". Enfatiza, em contraposição, como objeto científico próprio, "os intelectuais que produzem idéias e ideologias" visto que "constituem o mais importante dos elos entre dinâmica social e ideação" (MANNHEIM, 2001, p. 96).

Trata, o autor húngaro, da ampla trajetória social europeia, que parte do feudalismo e desenvolve o capitalismo, para explicar o surgimento da intelligentsia, desde estratos sociais minoritários como certos cavaleiros medievais, passando pelos humanistas, por ambientes intelectuais diversos como o mecenato e - já na modernidade - pelos cafés e salões no ascendente mundo urbanoindustrial (MANNHEIM, 2001, p. 97-113). Ele identifica nesses processos histórico-sociais um elemento comum: uma maior mobilidade e disponibilidade de agrupamentos sociais que vão se intelectualizando e se especializando no mundo da ciência e da arte, ao mesmo tempo demonstrando capacidade ou vocação acima da média para trocas de experiências com outros grupos sociais, de maneira que eram criadas perspectivas de vida reflexiva e multidimensional (MANNHEIM, 2001, p. 100).

O clero, camada pensante na sociedade feudal, corresponderia à intelligentsia. Contudo, a modernidade inaugura um novo sentido associado à intelligentsia. Por ser mais dinâmica do que as sociedades tradicionais, a sociedade moderna demanda uma atividade intelectual mais complexa. Tal atividade enseja um campo de especialização social e profissional que acompanha o desenvolvimento da moderna divisão social do trabalho, dentro dos marcos do capitalismo. Em consequência, a atividade intelectual não fica mais restrita ao saber erudito e exclusivo de uma elite.

A relevância da educação moderna, expressa na disseminação dos sistemas educacionais como suporte formativo do indivíduo, é um dos pressupostos sociais que garante a autoconsciência moderna, o despertar da consciência de cada grupo social, ampliando a diferenciação cultural. Dito de outro modo, a modernidade rompe com o monopólio do saber outrora nas mãos do clero, inaugurando uma dimensão pública e laica do ensino. Por conseguinte, a sociedade moderna desenvolve consigo um novo tipo de intelectual, relativamente desvinculado ou descompromissado em relação ao seu grupo/classe de origem, equipado com os conhecimentos científicos proporcionados pela educação, prestigiado por tal condição singular e apto a mediar as tensões presentes na sociedade (MANNHEIM, 2001, p. 89-93).

Assim, na perspectiva mannheimiana vai se configurando a intelligentsia como um 
tipo de estrato social delimitado, caracterizado por estabelecer vínculos flexíveis e diversos com outros grupos e classes sociais. Autônomo a ponto de não ser subsumido a grupos/classes próximos a ele, potente de tal maneira que é capaz de pensar de modo inovador sobre eles, os setores sociais não-intelectualizados:

"As situações de conflito só surgem quando grupos em mobilidade ascendente ou descendente, funcionando como amortecedor, ligam-se tanto aos estratos de cima quanto aos de baixo e adotam seus valores. É dessas situações, quando se torna possível o acesso a mundos até então separados, que se origina uma genuína intelligentsia" (MANNHEIM, 2001, p. 101).

Emancipando-se das "classes superiores", evitando aliar-se aos "estratos inferiores", procurando sempre "manter uma existência livre e independente", (MANNHEIM, 2001, p. 109) perdendo "seus contatos prévios com a sociedade", chegando a um "estado de isolamento social" ou mesmo à situação de "existência marginal numa sociedade de massa" (MANNHEIM, 2001, p. 110), a intelligentsia torna-se apta a se conectar mais eventualmente e menos organicamente a outros grupos sociais.

Como se vê, a perspectiva mannheimiana é facilmente oponível ao prisma teórico gramsciano, no qual mais fortes e estruturais são os laços necessários (pois pré-existentes) entre intelectuais e classes sociais. Na obra de Mannheim a intelligentsia é dotada de maior autonomia e agência em suas relações com o restante da sociedade, na qual se insere por meio de "amálgamas" (MANNHEIM, 2001) com tal ou qual estrato - noção a que recorre o autor húngaro justamente para salientar que os vínculos entre intelectuais e demais setores sociais são contingentes ou oportunos, não dados a priori.

Mannheim, dialogando com o marxismo, ilustra seu conceito de amálgama com o caso mesmo de intelectuais que vocalizam e formulam ideologias de classe:
"Os originadores de uma consciência de classe raramente pertencem ao estrato cuja autoconsciência despertam. É essa participação vicária numa situação de classe que fornece ao intelectual um ponto de apoio secundário na sociedade. Ele só pode precipitar as reações das massas penetrando na situação desta e assim transcendendo sua própria posição. Nesse processo, o indivíduo isolado adquire uma orientação coletiva através de prolongados contatos com uma classe à qual não pertence. Com efeito deve seguir para poder conduzir" (MANNHEIM, 2001, p. 117).

Seu exemplo remete diretamente à situação já concebida por Gramsci, de polarização ou intelectualização de indivíduos estimulada por classes sociais diferentes das de suas origens. Mas Gramsci acentua nesse fenômeno a força atrativa das classes e outros grupos sociais (do mundo circundante, inescapável aos intelectuais), enquanto Mannheim sublinha o desempenho ativo dos intelectuais em suas filiações societárias.

\section{Os intelectuais são um grupo social?}

Na tipologia gramsciana os intelectuais tradicionais - característicos da época anterior ao capitalismo - são aqueles caracterizados por possuírem espírito de grupo, sentirem sua continuidadehistórica e prezarem sua qualificação peculiar. Tais características normalmente fazem com que se tomem como independentes dos demais grupos sociais. Vivem como se fossem uma categoria social à parte. Gramsci é enfático ao ilustrar esse seu conceito com o caso do cosmopolitismo intelectual italiano, por ele tão criticado: "Trata-se (...) de um sentimento de 'intelectuais', que sentem a continuidade de sua categoria e de sua história, única categoria que teve sua história ininterrupta" (GRAMSCI, 1985, p. 58).

Face a esse continuum histórico, tais intelectuais aparentados a uma casta, distantes das camadas populares medievais, se consideravam uma classe paralela às outras, autônoma inclusive diante da classe dominante dos senhores feudais ${ }^{8}$. Sem dúvida que esse processo social 
de longas raízes impactou a conceituação referida aos intelectuais. Gramsci traduziu-o em chave crítica, como temos visto, ao passo que Mannheim não deixa de explorar positivamente tal "autonomia dos cultos" (VIEIRA, 2008, p. 75).

Por isso também o conceito gramsciano de intelectual tradicional expressa algum ruído no conjunto de seu empreendimento teóricoanalítico, centrado em uma compreensão societária englobante dos intelectuais eno desvelar dos liames que os condicionam socialmente, costumeiramente negados ou desprezados pela intelectualidade tradicional. Em sentido contrário, a preocupação de Mannheim com as especificidades da intelligentzia talvez enfrente menor resistência social para sua recepção.

Como Mannheim, Gramsci faz uma rica descrição da formação de setores intelectuais, que se dá conforme "processos históricos tradicionais". Na Europa, há camadas sociais que habitualmente disponibilizaram indivíduos para transcursos intelectualizantes, segundo a distribuição de oportunidades econômicas e as diversas aspirações profissionais: pequenas e médias burguesias, especialmente as rurais. A concentração da atividade intelectual em determinados grupos sociais e as características próprias dos intelectuais que os identificam socialmente também estão presentes nas reflexões gramscianas:

"A relação entre os intelectuais e o mundo da produção não é imediata, como é o caso nos grupos sociais fundamentais, mas é 'mediatizada', em diversos graus, por todo o contexto social, pelo conjunto das superestruturas, do qual os intelectuais são precisamente os 'funcionários"' (GRAMSCI, 1985, p. 10).

A intelectualidade no pensamento gramsciano é concebida no bojo das superestruturas de toda sociedade, todavia, diferentemente de Mannheim, tal fato não a desvincula das relações necessárias com os grupos sociais, pois ela representa interesses das classes em luta.

Tal visão não muito dignificante dos intelectuais como comissários subalternos a cumprir funções organizativas e conectivas, especificamente dos grupos socialmente dominantes, no que tange à hegemonia políticocultural na sociedade civil e à coerção legal no plano estatal (GRAMSCI, 1985, p. 10-11), pouco condiz com a auto-imagem que os intelectuais recorrentemente cultivam de si, inclusive na modernidade. De fato, trata-se de uma "dessacralização do intelectual como agente político" (VIEIRA, 2008, p. 78).

Em oposição, para Mannheim a intelligentzia é "um fenômeno tão evasivo e ambivalente" que não pode ser reduzido à divisão de classes e a uma funcionalidade aparentemente mais estrita - da atividade intelectual (MANNHEIM, 2001, p. 85).

Gramsci reconhece que sua conceituação amplia a abrangência empírica do fenômeno e causa estranhamento a quem tenha "preconceitos de casta" intelectual (GRAMSCI, 1985, p. 11; veja-se também VIEIRA, 2008, p. 76). Para ele, existe uma divisão de trabalho interna à intelectualidade, havendo uma verdadeira e real diferença qualitativa: no mais alto grau, devem ser colocados os criadores das várias ciências, da filosofia, da arte, etc.; no mais baixo, os 'administradores' e divulgadores mais modestos da riqueza intelectual já existente, tradicional, acumulada. (GRAMSCI, 1985, p. 11-12).

De qualquer maneira, o intelectual orgânico na teoria gramsciana parece ser o intelectual moderno por excelência, pois nele se apresenta nitidamente a performance políticocultural da intelectualidade em sua interação fundamental com o grupo social a que está associado e cujos interesses expressa.

Emerge aqui a relação dos intelectuais com o partido político moderno em Gramsci. Para alguns grupos sociais, o partido político é a forma principal de criação de seus intelectuais

8 No compasso desta auto-imagem social, a intelectualidade eclesiástica desenvolvia toda uma filosofia idealista, porteriormente criticada pelo marxismo. A respeito, ver Gramsci, 1985, p. 22. 
orgânicos diretamente no campo políticofilosófico e não no campo da técnica produtiva, bem como pode ser, também, o dispositivo que permite, na dimensão da sociedade civil, fundir intelectuais orgânicos do grupo dominante com intelectuais tradicionais. $\mathrm{Na}$ medida em que o partido político é capaz de cumprir sua tarefa primordial - desdobrar, a partir do grupo social definido de início economicamente, uma sociedade integral (civil e política), sob os auspícios de uma concepção sócio-cultural do mundo - todos os membros de um partido político são intelectuais (GRAMSCI, 1985, p. 1415).

Justamente por perceber os intelectuais em sua movimentação societária mais fluida e independente, Mannheim analisa de modo completamente diverso a conexão entre intelectuais e partidos políticos 9 . Para ele, a intelligentsia não pode formar partido próprio Gramsci diria o mesmo dos intelectuais, mas por outras razões. Como não é uma classe, ela carece de interesses comuns mais do que qualquer outro grupo social: "Nada poderia ser mais alheio a esse estrato que a mentalidade monolítica e a coesão". Embora afirme que um intelectual possa afinarse antes com grupos sociais afins do que com outro intelectual, ele critica as interpretações marxistas sobre os intelectuais, pois incapazes de enxergar a singularidade intelectual: "além de seus próprios interesses de classe distintos, os intelectuais introduzem em sua vocação intelectual uma motivação especial e uma atitude particular que o sociólogo não pode deixar de identificar" (MANNHEIM, 2001, p. 80).

Neste diapasão, o autor húngaro prossegue definindo e qualificando o objeto sociológico que construiu, parcialmente em oposição ao marxismo:

"A intelligentsia é uma camada intersticial; e a sociologia proletária, centrada que é em torno dos conceitos de classe e partido, não podia deixar de atribuir a esse agregado sem características de classe o papel de satélite de uma ou outra das classes e partidos existentes. Tal concepção naturalmente esconde as motivações peculiares do intelectual (...)." (MANNHEIM, 2001, p. 80)

Daí ele criticar tanto os intelectuais dedicados ao movimento operário como os ligados aos interesses burgueses (MANNHEIM, 2001, p. 137). Analogamente ao que ocorre com Gramsci e o intelectual tradicional, os intelectuais engajados nas classes em luta - exatamente os intelectuais orgânicos - são um fenômeno de difícil encaixe na conceituação mannheimiana, que eleva a status ontológico maior a intelligentsia que preza sua autonomia social: "Até agora, tem-se quase que exclusivamente enfatizado o aspecto negativo do 'desvinculamento' dos intelectuais, sua instabilidade social e o caráter predominantemente calculista de sua mentalidade" (MANNHEIM, 1986, p. 183).

Não por acaso, insiste: "A intelligentsia não pode construir uma ideologia de grupo própria: deve permanecer crítica de si própria, tanto quanto dos outros grupos" (MANNHEIM, 2001, p. 138). A motivação e a capacitação do intelectual, fundadas na abordagem de problemas sob várias perspectivas, o tornariam mais instável social e politicamente, embora possibilitem que ele visualize mais amplamente uma sociedade polarizada.

Assim, é possível avançar nas delimitações conceituais mannheimianas a respeito da intelligentsia, claramente desenhada como um estrato social específico: "Pode-se resumir as características essenciais desse grupo do seguinte modo: é um agregado situado entre e não acima das classes" (MANNHEIM, 2001, p. 81).

A capacidade particular da intelligentsia consiste, primeiramente, em não se curvar ao peso da influência das classes fundamentais da sociedade moderna. Ela se origina de "classes que se sentiam ameaçadas de cima e de baixo e que, por necessidade social, procuram escapar por um caminho intermediário" (MANNHEIM, 1986, p. 179). Alimentando-se de múltiplos setores sociais, a intelligentsia é, então, empoderada o suficiente

9 Ainda que Mannheim certamente não esteja operando com o conceito gramsciano de partido político. 
para oferecer alternativas diante dos conflitos. E a seguir o autor húngaro refina seu argumento, registrando que aquela capacidade de observar a modernidade de modo diferente da perspectiva das classes sociais "não virá provavelmente a ser desenvolvida por uma classe que ocupe uma posição intermediária, mas por um estrato relativamente sem classe, cuja situação na ordem social não seja demasiado firme" (MANNHEIM, 1986, p. 180).

Partindo do conceito de "intelligentsia socialmente desvinculada" de Alfred Weber, Mannheim busca evitar o que entende ser o critério analítico marxista, na reflexão sobre os intelectuais:

\begin{abstract}
"Mas os problemas de que estamos tratando não poderiam ser formulados adequadamente, e muito menos resolvidos, sem que abordássemos certas questões relativas à posição dos intelectuais. Uma Sociologia orientada apenas para a referência a classes sócio-econômicas jamais compreenderá adequadamente este fenômeno. De acordo com esta teoria, os intelectuais constituem uma classe, ou, pelo menos, um apêndice de uma classe“ (MANNHEIM, 1986, p. 180).
\end{abstract}

Para ele, os intelectuais não são "homogeneamente determinados", uma vez que há o "vínculo sociológico de unificação, ou seja, a educação, que os enlaça de modo surpreendente" (MANNHEIM, 1986, p. 180), o qual é capaz de minar - mas não fazer "desaparecer completamente" - "as diferenças de nascimento, status, profissão e riqueza" (MANNHEIM, 1986, p. 181).

Em segundo lugar, a intelligentsia, consoante o autor húngaro, possui maior capacidade de enxergar e analisar as diferentes tendências políticas e culturais expressas pelas classes, sem restringir-se às visões parciais de cada uma delas, oriundas de suas respectivas experiências sociais:

“(...) o homem instruído é determinado, quanto ao seu horizonte intelectual, de múltiplas maneiras. Essa herança cultural adquirida sujeita-o à influência de tendências opostas na realidade social, enquanto a pessoa cuja orientação face ao todo não se processa em virtude da sua instrução, mas que participa diretamente no processo social de produção, tende simplesmente a absorver a Weltanschauung desse grupo particular e a agir exclusivamente sob a influência das condições impostas por sua situação social imediata” (MANNHEIM, 1986, p. 181).

Aqui fica configurado que a atividade intelectual, em Mannheim, é mais concentrada socialmente nos intelectuais do que se verifica na perspectiva gramsciana. Enquanto nesta cada intelectualidade desenvolve uma visão social de mundo a partir da experiência produtiva original da classe a que está associada, na formulação mannheimiana a intelligentsia "estrato social em grande parte desvinculado de qualquer classe social" (MANNHEIM, 1986, p. 181), sem interesses concretos nítidos no plano econômico - está apta a ir além dos pontos de vista epistemológicos de todos os grupos sociais e a fundir os vários pontos de vista num todo coerente. Se tal diagnóstico certamente incrementa a capacidade de investigar os multifacéticos comportamentos intelectuais, por outro lado corre-se com ele o risco de algum fetichismo intelectual.

É o que se verifica em outras assertivas mannheimianas, tais como a de que a intelligentsia "resume em si mesmo todos os interesses que permeiam a vida social", determinada que é "por este meio intelectual que contem todos os pontos de vista contraditórios" (MANNHEIM, 1986, p. 182). O que significa dizer o mesmo que Gramsci ao asseverar que os intelectuais expressam em plano superior os interesses de todos os grupos sociais que disputam a hegemonia na sociedade, com a diferença - decisiva - que este fornece mais peso ontológico à sociedade, ao passo que o autor húngaro confere mais força à intelectualidade. Enquanto na obra do marxista italiano os intelectuais apenas articulam as tensões sociais no plano cultural e político sob a égide parcial de cada uma das classes em luta (VIEIRA, 2008, p. 78), para Mannheim a intelligentsia seria capaz de sintetizar as tensões sociais e 
as perspectivas teóricas correspondentes. $\mathrm{O}$ intelectual, pois, seria um perito do mundo social, o mais indicado para mediar conflitos sociais dado seu conhecimento científico a respeito. A sociologia do conhecimento seria a base racional legitimadora da intervenção social da intelligentsia como agente mediador único ou como "intérpretes privilegiados dos conflitos entre as diferentes visões de mundo" (VIEIRA, 2008, p. 75). Os antagonismos entre os grupos sociais e suas visões de mundo seriam superáveis.

Este poder da intelligentsia em Mannheim, qualitativamente superior aos dos grupos sociais ordinários, essa "pretensão de intervenção" (VIEIRA, 2008, p. 75), segue lógica inversa às formulações gramscianas, as quais ressaltam a funcionalidade dos intelectuais para as classes em luta, estas sim senhoras das experiências ontológicas fundamentais de toda sociedade, irresoluvelmente conflituosa nos marcos do capitalismo.

A singularidade das aptidões intelectuais sublinhadas por Mannheim se verificaria inclusive quando de engajamentos de classe, que costumam ser explorados analiticamente pelo marxismo:

"Esta capacidade de se vincularem a classes a que originalmente não pertenciam era possível aos intelectuais porque eles podiam adaptar-se a qualquer ponto de vista e porque eram os únicos em condições de escolher sua filiação, ao passo que os indivíduos imediatamente ligados por filiações de classe somente em raras exceções se mostravam capazes de transceder os limites de sua visão de classe" (MANNHEIM, 1986, p. 185).

Invertendo-se a imagem gramsciana do intelectual-funcionário do grupo social a que se conecta, no prisma mannheimiano é o intelectual que conduz ou orienta os demais setores sociais:

"Sua função consiste em penetrar nas fileiras dos partidos em conflito, de modo a obrigá-los a aceitar suas demandas. Esta atividade, considerada em termos sociológicos, demonstrou, amplamente, em que ponto residem a peculiaridade sociológica e a missão deste estrato social desvinculado" (MANNHEIM, 1986, p. 185).

A missão intelectual, então, já pintada em cores cientificistas, realiza no "processo social total" o que está vedado a cada grupo social em particular (e a todos os seus membros que perfazem cotidianamente atividades intelectuais, mesmo não sendo nelas especializados, diria Gramsci, em sentido oposto), sendo exclusivo da intelligentsia: "a descoberta da posição que possibilitasse uma perspectiva total. Desse modo, poderiam desempenhar o papel de vigias no que, de outra forma, seria uma noite impenetrável" (MANNHEIM, 1986, p. 185) ${ }^{10}$.

A capacidade única de intelectuais produzirem "uma orientação total mesmo depois de ingressarem em um partido" e se interessarem "em perceber o conjunto da estrutura social e política" (MANNHEIM, 1986, p. 186) parece colocar a intelligentsia acima das classes sociais, não entre elas, ainda que o sociólogo húngaro diga o contrário, como já visto (MANNHEIM, 2001, p. 81). O que parece confirmado por outra passagem sua, de caráter normativo: "espera-se que este grupo médio dinâmico se esforce para criar um foro, alheio às escolas de partido, que salvaguarde a perspectiva do todo e o interesse pelo todo" (MANNHEIM, 1986, p. 186).

Completa-se então a defesa mannheimiana da "possibilidade da política como ciência", papel estrategicamente reservado à intelligentsia: "Seria tanto melhor que aqueles intelectuais que trazem pronunciados interesses de classe viessem, especialmente na juventude, a assimilar o ponto-de-vista e a concepção do todo" (MANNHEIM, 1986, p. 187).

A inserção no mundo da educação e o manejo privilegiado da cultura, segundo a perspectiva mannheimiana, produziriam padrões de conduta e discurso distintos dos

10 Neste sentido, discordamos de Vieira (2008, p. 74) quando afirma que Mannheim "não se tenha dedicado especificamente à análise da função dos intelectuais”. 
vigentes nos indivíduos não-intelectualizados, presos que estão ao âmbito de suas situações vitais (MANNHEIM, 2001, p. 89-93).

Aquievidencia-sequãovigorosaéaagência dos intelectuais na sociologia de Mannheim, já que subentende-se que a intelligentsia pode ir além da "situação vital" (MANNHEIM, 2001, p. 93) ou "ultrapassar as visões determinadas pelos vieses produzidos e internalizados pelas condições sociais de existência" (VIEIRA, 2008, p. 75), destino a que os demais grupos sociais não podem escapar. Mas esta capacidade exclusiva da intelectualidade não faz com que ignoremos os determinantes ou condicionantes sociais de sua própria existência? O que pode Mannheim estar estabelecendo nesse ponto é a especificidade da "situação vital" dos próprios intelectuais: digna, porém também inexorável.

Neste sentido, a transcendência da intelectualidade pode ser problematizada. É admissível que o olhar singular dos intelectuais consubstancie um estilo de pensar mais cético e menos rígido (MANNHEIM, 2001, p. 123). Todavia, não é fácil aceitar uma certa hierarquização proposta por ele, na qual a intelligentsia monopolize os segredos que explicariam toda a sociedade e seus grupos componentes, garantido sua autonomia por meio do prestígio social da ciência ${ }^{11}$. Na obra de Gramsci as classes sociais (e também outros estratos sociais) mantêm sua agência forte o suficiente para comportar atividades intelectuais que as habilitam a compreender e manejar soberanamente o mundo social.

\section{Lugares sociais e ação intelectual}

Gramsci, em chave anti-individualista, referência os intelectuais aos grupos sociais em geral e às classes sociais em particular. Contudo, e a par do internacionalismo comunista a que se filia, o marxista italiano postula uma centralidade da sociedade nacional na contextualização e compreensão das ações dos intelectuais: "uma invenção ou descoberta perde o caráter individual e casual e pode ser julgada nacional quando o indivíduo for estreita e necessariamente ligado a uma organização da cultura que tenha caráter nacional" (GRAMSCI, 1985, p. 71).

Ele é um ácido crítico do cosmopolitismo intelectual italiano, originário do papel europeu e universalizante da Igreja Católica sediada no Vaticano, que impedia um desempenho significativo da intelectualidade em relação às suas raízes nacionais: "os inventores individuais podem ser ligados a correntes culturais e científicas que tiveram origem e desenvolvimento em outros países, em outras nações" (GRAMSCI, 1985, p. 71; veja-se também VIEIRA, 2008, p. 7677). Certamente que a tardia integração nacional italiana preocupava Gramsci e incidia sobre suas reflexões. Assim, ele aponta que os intelectuais italianos da época medieval escreviam para a Europa cristã, não para a Itália. A organização eclesiástica seria um organismo tradicional que assimila aos seus quadros indivíduos singulares, mas na perspectiva da superação de suas origens sociais pelo caráter de casta. Um possível sentimento nacional é, então, sufocado, face também à força do Papado no território italiano (GRAMSCI, 1985, p. 27-28 e 34).

Enfrentando tal legado, visto como peculiar fardo histórico nacional, Gramsci faz a crítica do cosmopolitismo intelectual, fenômeno que restringe a ação intelectual à circulação de ideias entre intelectuais de várias regiões e países, excluídas as massas populares de tal vida cultural, caracterizada, pois, como elitizada: “a 'originalidade' consiste tanto em 'descobrir' quanto em 'aprofundar', em 'desenvolver' e em 'socializar' (...) precisamente nestes campos, manifesta-se a energia nacional, que é coletiva” (GRAMSCI, 1985, p. 71). Daí seu olhar negativo para comunidades intelectuais auto-centradas apreciação a priori inversa à de Mannheim, como já visto.

Neste ínterim, fecha-se o cerco antiindividualista gramsciano a respeito dos 
intelectuais, acrescido de um nacionalismo metodológico nem sempre visível em sua obra:

"A força expansiva, a influência histórica de uma nação, não pode ser medida pela intervenção individual de pessoas singulares, mas pelo fato de que estas pessoas singulares expressem consciente e organicamente um bloco social nacional." (GRAMSCI, 1985, p. 67)

Coerente com a ênfase teórica coletivista do marxismo, Gramsci mensura a performance social dos intelectuais segundo uma baliza sociológica concretizada na sua contribuição específica para o grupo social a que se irmana. De certa forma, o mérito dos intelectuais não seria inerente ao produto de sua atividade, pois eles dependem da existência de um certo público nacional que os valorize e com quem mantenham relações orgânicas. O marxista italiano postula, então, a integração do intelectual com a sociedade nacional, conformada pelas fronteiras do EstadoNação, como relação necessária e paradigmática entre intelectual e sociedade na modernidade capitalista.

A respeito, a França, com a qual a Itália é comparada negativamente, seria exemplar como é recorrente quanto à superação do Antigo Regime, dado o marco da Revolução Francesa. Nela, a burguesia ascendente e seus intelectuais (orgânicos, portanto) teriam desenvolvido lutas políticas e culturais em todas as frentes sociais, exercendo uma função cosmopolita de sentido claramente nacional. Correndo o risco de tomar a França como modelo, e assim analisar pejorativamente outras sociedades no que tange ao desempenho de seus intelectuais na nascente modernidade, Gramsci visualiza o caso britânico quase como o inverso. Dotada de uma burguesia muito forte economicamente, mas inexpressiva em termos políticos e intelectuais, a Inglaterra seria o terreno histórico da assimilação das antigas classes territoriais enquanto intelectualidade tradicional da burguesia britânica. Por sua vez, a Alemanha reuniria características comuns à Inglaterra e à Itália. De integração nacional tardia como a italiana, por conta do supranacionalismo do Sacro Império Romano-Germânico, e dominada politicamente pela classe territorial dos junkers, a Alemanha veria este estrato social cumprir o papel de intelectuais tradicionais de sua burguesia industrial - como se dava no caso britânico (GRAMSCI, 1985, p. 16-22).

Conclui-se, pois, não apenas que a sociedade nacional seria o lugar social por excelência da ação intelectual na modernidade capitalista, mas também que intelectuais orgânicos ou tradicionais - desempenham funções de articulação política e cultural das classes sociais a que se vinculam.

Percebe-se, a esta altura, que por meio do conceito de intelectual tradicional Gramsci logra dar conta de processualidades históricas que fogem ao padrão configurado pelo intelectual orgânico, de homogeneidade social entre classe, por um lado, e intelectualidade a seu serviço, por outro. E não apenas estratos sociais tradicionais se mostraram capazes de representar/ vocalizar os projetos societários das burguesias modernas: em vários países europeus, também o movimento operário e socialista formou política e intelectualmente indivíduos, e mesmo grupos sociais inteiros, que posteriormente passaram a atender aos interesses de outras classes (GRAMSCI, 1985, p. 52).

O fato de a Alemanha ter possuído um agrupamento social, ainda então dominante, configurado como intelectualidade tradicional da moderna burguesia, "mas com privilégios especiais e com uma forte consciência de ser um grupo social independente" (GRAMSCI, 1985, p. 18), nos leva de volta à Mannheim. Este passado histórico, recente para o sociólogo húngaro radicado na Alemanha (e depois na Inglaterra), teria impactado a conceituação mannheimiana da intelligentsia, de sorte que ele filtrou e traduziu tal legado na direção da valorização teórica da desvinculação ou autonomia desse estrato social intelectualizado?

A resposta à indagação parece ser afirmativa. Enquanto Gramsci acentua a força da classe burguesa ao polarizar política e culturalmente grupos sociais mais antigos de acordo com seus interesses e projetos, Mannheim 
realça a ativa empatia da moderna intelligentsia, sua "capacidade de 'por-se no lugar do outro", seu "desejo de penetrar em pontos de vista desconhecidos ou desnorteantes" (MANNHEIM, 2001, p. 93). Valoriza ele, novamente mas de outra maneira (diversa da do ceticismo intelectual), a agência dos intelectuais. Estes, seu alvo científico privilegiado, embora suas pesquisas e reflexões partam da sociologia do conhecimento e, por conseguinte, de uma "concepção dinâmica da verdade", respaldada nos grupos sociais antes que nos indivíduos (MANNHEIM, 1986).

Daí Mannheim ter consagrado algumas lições metodológicas fundamentais para a investigação dessa agência, isto é, das ações e iniciativas dos intelectuais, notadamente os "antecedentes sociais do indivíduo", bem como a fase específica da curva da carreira - se ele está em ascensão, no auge ou em descenso; se ele ascende individualmente ou enquanto membro de um grupo; se ele se encontra bloqueado em seu avanço ou decaído à sua situação inicial; a fase de um movimento social do qual participa - inicial, média ou final; a posição de sua geração em relação a outras; seu habitat social; e finalmente, o tipo de agrupamento no qual desenvolve suas atividades (MANNHEIM, 2001, p. 127-128).

A par dessa sua perspectiva analítica empoderadora da performance dos intelectuais, Mannheim chega ao diagnóstico de que a intelligentsia livre estaria em declínio na modernidade. Diante da polarização social envolvendo grandes blocos político-ideológicos institucionalizados, vigente na Europa nas primeiras décadas do século XX, a independência crítica da intelectualidade estava em perigo, assim como seu substrato liberal:

“(...) o processo intelectual aqui descrito não passa de um aspecto do liberalismo entendido de modo amplo (...). A abdicação do liberalismo quase pôs fim à era da avaliação crítica (...). O liberalismo e a livre ideação não passam de episódios entre períodos de cultura institucional." (MANNHEIM, 2001, p. 135)

Em direção contrária certamente afirmaria Gramsci, para quem a intelectualidade não só não pode ser um grupo social à parte como também sua autonomia seria relativa, pois necessariamente referida aos lugares que ocupa nos conflitos da moderna sociedade nacional. Para tanto, aludimos com ele a um autor alemão, certamente familiar a Mannheim:

"Com Hegel, começa-se a não mais pensar segundo as castas ou os 'estados', mas segundo o 'Estado', cuja 'aristocracia' são precisamente os intelectuais. (...) Sem esta 'valorização' dos intelectuais feita por Hegel não se compreende nada (historicamente) do idealismo moderno e de suas raízes sociais" (GRAMSCI, 1985, p. 56).

\section{Conclusão}

A oposição sociológica entre intelectualidade gramsciana e intelligentsia mannheimiana, aqui explorada, antecede historicamente às obras dos dois autores. O marxismo dos bolcheviques já trazia críticas à intelligentsia russa, caracterizada como um setor da classe dominante que, embora envolto na cena política, se imaginava acima dos interesses das classes em luta - revelando então suas posturas elitista e cientificista (VIEIRA, 2008, p. 69-70). Com as formulações de Gramsci, tornava-se ainda mais nítido entre os marxistas o repúdio à ideia de um estrato social autônomo que, "gozando de capacidades superiores de análise e de elaboração de propostas sociais", pudesse ser considerado um "protagonista político privilegiado" (VIEIRA, 2008, p. 69-70).

Não por acaso o comunista italiano aponta a conjugação entre elites intelectuais e Estado, que a nosso juízo corresponde em boa medida ao fenômeno e ao conceito de intelligentsia:

Aliás, ocorre que muitos intelectuais pensem ser o Estado: crença esta que, dado o imenso número de componentes da categoria, tem por vezes notáveis conseqüências e leva a desagradáveis complicações para o grupo fundamental econômico que é realmente o Estado. (GRAMSCI, 1985, p. 15 negrito do autor) 
A identificação de certa intelectualidade diretamente com o poder político centrado na dominação exercida estatalmente, antes que com a participação política vinculada a classes sociais em luta (notadamente as populares/ subalternas), certamente remonta ao Platão de $A$ República. Passa também por outras experiências históricas de atuação política de intelectuais: Cícero, Maquiavel, Voltaire (VIEIRA, 2008, p. 71-72). E se consagra na modernidade, com a complexificação das esferas cultural eeducacional, que fortaleceu socialmente os intelectuais, conforme já visto com Mannheim. Ademais, se faz presente nas próprias origens da sociologia como disciplina científica, que nasce em parte como uma engenharia social (ADORNO, 2008), eivada do que contemporaneamente chamamos de tecnocracia. O positivismo comtiano é emblemático neste sentido.

Como antes exposto por Gramsci, por trás do Estado está a moderna dominação de classe do "grupo fundamental econômico", a burguesia. É possível vincular Mannheim a tal tensão histórica e política, ainda que suas reflexões se façam em direção sociocêntrica, bem como a uma certa tradição do pensamento alemão que remonta ao menos a Hegel (algo também registrado por Gramsci, mas referido à intelectualidade moderna como um todo). Vertente que foi combatida pelo nascente marxismo: "Marx dedicou-se particularmente (...) a refutar a tese hegeliana segundo a qual a burocracia exercia uma função mediadora entre os diversos grupos sociais, agindo desse modo como 'classe universal' no interesse de todos" (McLELLAN, 1979, p. 72).

Glaucia Villas Boas, analisando a recepção da sociologia alemã no Brasil, destaca entre outros autores e obras, Ideologia e Utopia de Mannheim. Ela chama atenção para o fato de nossos sociólogos da década de 1950 e anos seguintes, adeptos da modernização do país, terem se interessado por seu arsenal conceitual em torno da intelligentsia, adequado para justificar "uma participação singular dos intelectuais/cientistas no domínio da política".
No seu diagnóstico, eles valorizavam "as ideias que justificavam seus ideais, sem que houvesse interesse em examinar com mais acuidade os fundamentos" das obras dos sociólogos atuantes na Alemanha, Mannheim incluído (BOAS, 1997, p. 78).

Não nos parece, contudo, ser o caso das elaborações de Mannheim. No decurso da revisão analítica que aqui efetuamos, entendemos que suas formulações fazem jus a uma apreensão teórica em que o sentido maior reside no empoderamento sócio-político dos intelectuais.

Ainda mais se pensarmos na trajetória histórica da sociedade e do pensamento brasileiros, na qual se destaca uma tradição reformista, nacionalista e estatólatra de certas elites políticas e intelectuais (BRANDÃO, 2005; ver também PERRUSO, 2017, p. 16), que são tidas como modernizantes mas também, ressaltamos, podem ter afinidade ou inspiração mannheimiana. Ao se predisporem como assessores do poder do Estado na caminhada modernizante de que a Nação necessitaria, diante da suposta inoperância de nossas classes, parte da intelectualidade brasileira se configurava como uma intelligentsia de atuação política legitimada cientificamente por sobre os demais grupos sociais - aos quais os mesmos intelectuais não acreditavam-se vinculados...

Neste ponto, concordamos com Vieira quando afirma que "a tese do intelectual como mediador político permanece em circulação no debate acadêmico e político", mas dele discordamos quanto à assertiva imediatamente anterior: "ainda que a ideia da síntese das perspectivas não encontre muitos defensores contemporaneamente" (VIEIRA, 2008, p. 75-76). Pois não é a nossa resiliente ideologia nacionalista ou (neo)desenvolvimentista o instrumento histórico de promoção estatal que sempre buscou o crescimento econômico capaz de bem atender a todos os segmentos sociais?

Cenário adverso teria sido o da recepção de Gramsci no Brasil no que tange às suas reflexões sobre os intelectuais, pois o pensamento marxista deve procurar suas bases sociais de legitimação nas lutas das classes populares/subalternas, nem 
sempre devidamente visibilizadas na história nacional (PERRUSO, 2017).

Por outro lado, a influência e a recepção dos conceituais mannheimianos em torno da intelectualidade, ressaltando a ativa autonomia dos membros deste agrupamento, podem nos levar a um lugar social e institucional seu que será dominante no século XX: as universidades, o mundo acadêmico. Objeto que será abordado em um segundo artigo sobre conceituais referidos aos intelectuais, tratando de outros autores do campo temático em questão.

\section{Referências bibliográficas}

ADORNO, Theodor. Introdução à Sociologia. São Paulo: Ed. Unesp, 2008.

BIANCHI, Álvaro. "Dossiê Gramsci e a política Apresentação". Revista de Sociologia e Política, n. 29, nov. 2007, p. 7-13.

BOAS, Glaucia Villas. "A recepção da sociologia alemã no Brasil. Notas para uma discussão". BIB, n. 44, jul./dez. 1997, p. 73-80.

BOSI, Alfredo. "O trabalho dos intelectuais segundo Gramsci”. Debate e Crítica, n. 6, 1975, p. 105-113.

BRANDÃO, Gildo Marçal. "Linhagens do pensamento político brasileiro". Dados, v. 48, n. 2, 2005, p. 231-269.

CEPÊDA, Vera Alves; MAZUCATO, Thiago \& FONTANA, Felipe (orgs.). Interfaces da Sociologia do Conhecimento de Karl Mannheim. São Carlos: Ed. Ufscar, 2015.

DURIGUETTO, Maria Lúcia. "A questão dos intelectuais em Gramsci". Serviço Social \& Sociedade, n. 118, abr./jun. 2014, p. 265-293.

GRAMSCI, Antonio. Os Intelectuais $e$ a Organização da Cultura. 4a.ed. Rio de Janeiro: Civilização Brasileira, 1985.
LYNCH, Christian Edward Cyril Lynch. "Cartografia do pensamento político brasileiro: conceito, história, abordagens". Revista Brasileira de Ciência Política, n. 19, abr. 2016, p. 75-119.

MANNHEIM, Karl. Ideologia e Utopia. 4a.ed. Rio de Janeiro: Guanabara, 1986.

Sociologia da cultura. 2a.ed. São Paulo:

Perspectiva, 2001.

MATIAS, Glauber Rabelo. "Intelectuais como missão: revisitando Karl Mannheim”. Urutágua, n. 11, 2007, p. 1-12.

McLELLAN, David. "A Concepção Materialista da História". In: HOBSBAWN, Eric et al. História do Marxismo I - O Marxismo no Tempo de Marx. Rio de Janeiro: Paz e Terra, 1979.

NOSELLA, Paolo. A escola de Gramsci. São Paulo: Cortez, 2004.

PERRUSO, Marco Antonio. "Revendo mapeamentos do pensamento brasileiro". Em Tese, v. 14, n. 1, jan./jun. 2017, p. 12-30.

SHIOTA, Ricardo Ramos. "Política e conhecimentos parciais: a intelligentsia enquanto fundamento social da síntese em Karl Mannheim". Aurora, n. 4, jul. 2009, p. 57-64.

VIEIRA, Carlos Eduardo. "Intelligentsia e intelectuais - sentidos, conceitos e possibilidades para a história intelectual". Revista Brasileira de História da Educação, n. 16, jan./abr. 2008, p. 63 85. 